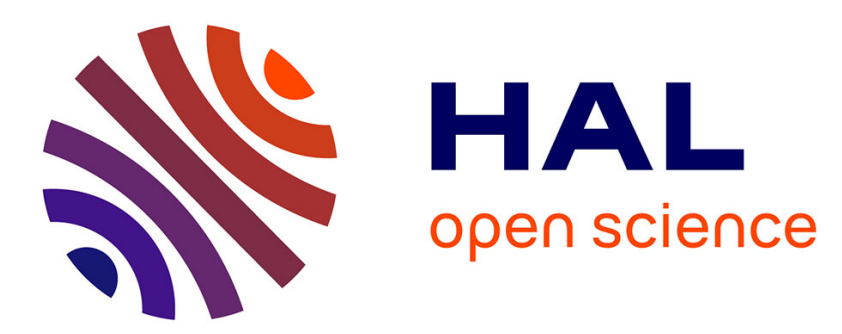

\title{
Experimental evidences of distinct heat transfer regimes in Pulsating Heat Pipes (PHP)
}

Stéphane Lips, Ahlem Bensalem, Yves Bertin, Vincent Ayel, Cyril Romestant, Jocelyn Bonjour

\section{- To cite this version:}

Stéphane Lips, Ahlem Bensalem, Yves Bertin, Vincent Ayel, Cyril Romestant, et al.. Experimental evidences of distinct heat transfer regimes in Pulsating Heat Pipes (PHP). Applied Thermal Engineering, 2010, 30 (8-9), pp.900-907. 10.1016/j.applthermaleng.2009.12.020 . hal-00621285

\section{HAL Id: hal-00621285 \\ https://hal.science/hal-00621285}

Submitted on 10 Sep 2011

HAL is a multi-disciplinary open access archive for the deposit and dissemination of scientific research documents, whether they are published or not. The documents may come from teaching and research institutions in France or abroad, or from public or private research centers.
L'archive ouverte pluridisciplinaire HAL, est destinée au dépôt et à la diffusion de documents scientifiques de niveau recherche, publiés ou non, émanant des établissements d'enseignement et de recherche français ou étrangers, des laboratoires publics ou privés. 


\section{Accepted Manuscript}

Experimental evidences of distinct heat transfer regimes in Pulsating Heat Pipes (PHP)

Stéphane Lips, Ahlem Bensalem, Yves Bertin, Vincent Ayel, Cyril Romestant, Jocelyn Bonjour

PII:

S1359-4311(10)00003-7

DOI:

10.1016/j.applthermaleng.2009.12.020

Reference:

ATE 2957

\section{APPLIED \\ THERMAL \\ ENGINEERING}

To appear in:

Applied Thermal Engineering

Received Date: $\quad 20$ July 2009

Accepted Date: $\quad 27$ December 2009

Please cite this article as: S. Lips, A. Bensalem, Y. Bertin, V. Ayel, C. Romestant, J. Bonjour, Experimental evidences of distinct heat transfer regimes in Pulsating Heat Pipes (PHP), Applied Thermal Engineering (2010), doi: 10.1016/ j.applthermaleng.2009.12.020

This is a PDF file of an unedited manuscript that has been accepted for publication. As a service to our customers we are providing this early version of the manuscript. The manuscript will undergo copyediting, typesetting, and review of the resulting proof before it is published in its final form. Please note that during the production process errors may be discovered which could affect the content, and all legal disclaimers that apply to the journal pertain. 


\title{
Applied Thermal Engineering
}

\section{Experimental evidences of distinct heat transfer regimes in Pulsating Heat Pipes (PHP)}

\author{
Stéphane Lips ${ }^{a}$, Ahlem Bensalem ${ }^{b}$, Yves Bertin ${ }^{b}$, Vincent Ayel ${ }^{\text {, }}$ Cyril Romestant $^{\text {b }}$, \\ Jocelyn Bonjour ${ }^{\mathrm{a}}$
}

a. Université de Lyon, CNRS

INSA-Lyon, CETHIL, UMR5008, F-69621, Villeurbanne, France

Université Lyon 1, F-69622, France

Tel: +33 4.72.43.64.27,Fax:+33 4.72.43.88.11,jocelyn.bonjour@insa-lyon.fr

${ }^{\text {b. }}$ LET, UMR CNRS ENSMA 6608

1, avenue Clément ADER 86961 Futuroscope CHASSENEUIL Cedex, France

Tel: +335494981 12, Fax: +335498101

\begin{abstract}
Various experiments were conducted on two full-size Pulsating Heat Pipes (PHP) which differed from their diameter, number of turns, and working fluid. The analysis of the experimental results showed two kind of operating curves (overall thermal resistance vs. heat rate): for low heat fluxes, the curve is irregular and the PHP performance is sensitive to the orientation. For high heat fluxes, the operating curve is smooth and independent from the orientation. To contribute to the analysis of these results, experiments were conducted at the
\end{abstract}


scale of a single branch of a PHP. An oscillating motion was imposed to a single liquid plug surrounded by two vapour slugs in a capillary tube and high speed visualisations were performed. The test section was either adiabatic or heated. The adiabatic experiments brought to the fore the importance of dynamic contact angles in the flow and the dissymmetry between the advancing and receding contact angle. The non-adiabatic experiments showed that at low flux, the flow is disturbed by bubble nucleation, while at high heat flux, the main heat transfer mechanism is thin film evaporation, with a completely different thermal and hydrodynamic behaviour.

Keywords:

Pulsating heat pipe, oscillating flow, two-phase flow, thin film evaporation, nucleation

$\begin{array}{ll}\text { Nomenclature } & \\ \text { Bo } & \text { Bond number } \\ \text { C } & \text { constant of eq. (1) } \\ \text { D } & \text { diameter, } \mathrm{m} \\ \mathrm{g} & \text { acceleration of gravity, } \mathrm{m}_{\mathrm{s}}{ }^{-2} \\ \mathrm{~L} & \text { length, } \mathrm{m} \\ \mathrm{N} & \text { number of turns } \\ \dot{\mathrm{Q}} & \text { heat input rate }(\mathrm{W}) \\ \mathrm{R} & \text { thermal resistance, K/W } \\ \mathrm{r} & \text { meniscus curvature radius, } \mathrm{m} \\ \mathrm{r} & \text { dimensionless radius } \\ \mathrm{T} & \text { temperature, } \mathrm{K} \\ \mathrm{t} & \text { time, } \mathrm{s} \\ \mathrm{u} & \text { velocity m/s }\end{array}$

\section{Greek}




$\begin{array}{ll}\Delta \mathrm{P}_{\mathrm{f}} & \text { frictional pressure drop, } \mathrm{Pa} \\ \mu & \text { dynamic viscosity, Pa.s } \\ \rho & \text { density, } \mathrm{kg} / \mathrm{m}^{3} \\ \sigma & \text { surface tension } \mathrm{N} / \mathrm{m}\end{array}$

\section{Subscripts}

$\begin{array}{ll}\text { crit } & \text { critical } \\ \text { cryo } & \text { cryostatic bath } \\ \text { e } & \text { evaporator } \\ 1 & \text { liquid } \\ \text { sat } & \text { saturation } \\ \text { v } & \text { vapour } \\ \text { w } & \text { wall } \\ 1,2 & \text { refers to PHP1 or PHP2 }\end{array}$

\section{Introduction}

Since a few years, Pulsating Heat Pipes (PHPs) have been the subject of research in an increasing number of laboratories. As a matter of fact, their thermal performance and the simplicity of their design make them potential candidates for a great number of applications. PHPs were presented in 1971 by Smyrnov in a Russian Patent, and in 2003 in a U.S. patent [1]. PHP in the form as they are investigated today have been first proposed by Akachi [2]. A PHP mainly consists of a meandering tube of capillary dimensions with many U-turns as shown on Fig. 1 [3]. Contrarily to conventional heat pipes, a PHP does not include any capillary structure inside the tube. Because of the small size of the tube, the working fluid distributes itself naturally into the form of liquid slugs and vapour plugs. As in conventional heat pipes, heat is provided at one end of the PHP (evaporator) and dissipated to a heat sink at the other end (condenser), with an adiabatic zone between them. The heat transport is ensured by the oscillations of the slugs and plugs in the tube, which are believed to be due to 
thermally-induced pulsations of pressure and to a complex combination of two-phase flow instabilities. However, the understanding of the phenomena governing the PHPs behaviour is still limited and further studies are needed.

Khandekar [3] conducted a large number of experiments for various PHP configurations. He performed an analysis of the impact of several parameters on their behaviour (filling ratio, heat input, number of turns, orientation,...). He gained from his experiments an improved understanding of the heat and fluid flow mechanisms in PHPs. He discussed to effect of the tube diameter that should be small enough to ensure the flow oscillations, i.e. smaller than a critical value:

$$
\mathrm{D}<\mathrm{D}_{\text {crit }}=\mathrm{C} \cdot \sqrt{\frac{\sigma}{\text { g. }\left(\rho_{1}-\rho_{\mathrm{v}}\right)}}
$$

with $\mathrm{C}$ being a constant of about 2 .

Khandekar et al. [4] also performed some flow visualisations during the operation of a PHP. They distinguished four regimes that can be related to the PHP operating curve (overall thermal resistance of the heat pipe as a function of the input power): at low heat input, the oscillations amplitude remains limited, and the thermal resistance slightly decreases with the increase of the heat input. At higher heat input, the decrease of the thermal resistance is more noticeable, and this corresponds to a slug flow pattern. Nevertheless, when increasing the heat input, a preferred flow direction progressively appears. When this preferred flow direction is clearly established, and when the flow pattern is annular rather than of slug type, the thermal resistance is minimum and exhibits a plateau. Finally, at high heat flux, the thermal resistance 
strongly increases with the increase of the heat input; this regime corresponds to a dryout of the evaporator. Additional information was provided by Khandekar et al. [5] in their experiments with three different fluids (ethanol, water, R-123). For ethanol and water, the critical diameter was much larger than the tube diameter, while for the latter, the critical diameter was of the order of (or even slightly lower than) the tube diameter. According to their experiments, the effect of bubbles on the two-phase oscillating flow that develops out of the extreme operational limits of PHPs (i.e. PHP completely empty or completely filled with liquid) depends on the filling ratio and on the PHP orientation. At high filling ratio (e.g. 95\% of liquid) and favourable orientation (evaporator at bottom, condenser at top), the bubbles tend to limit the two-phase fluid motion. For a moderate filling ratio (about $20 \%-70 \%$, which actually gives birth to oscillations), gravity was shown to play a role even for water, i.e. even for a critical diameter noticeably greater than the tube diameter (highly confined situation), while with R-123, the PHP was found to operate, in spite of a critical diameter slightly lower than the tube diameter. All these observations were interpreted through the effect of bubbles on the two-phase flow too.

Riehl [6] used various working fluids and tested an open loop PHP in different orientations. He compared the thermal performance of a PHP working with water, ethanol, propanol, methanol and acetone. In his experimental conditions, the use of methanol and acetone led to the best thermal performance whereas the use of water led to the worst.

Moreover, he observed that the oscillations in the PHP are more important and more regular with methanol than with water. This was explained by the low latent heat of the methanol which promotes nucleation and boiling and, as a consequence, instabilities of the fluid flow. Finally, he observed best thermal performance in horizontal orientation compared to vertical 
orientation. However, the importance of the effect of orientation depends on the fluid used: with ethanol and methanol, the ratio of the thermal resistances in horizontal and vertical orientation is more than two, whereas with water, thermal performance is almost independent of the orientation.

$\mathrm{Xu}$ et al. [7] visualized the oscillating flow in a closed loop PHP with a high speed camera. For methanol and water, various oscillation modes were observed. Moreover coalescence and vapor plug break-up phenomena were highlighted with water as the working fluid, particularly in the tubes U-bends. Their interpretation, based on an analytical model, was that the capillary pressure is not uniform in the bends, which results in a local accumulation of liquid. They also stated that, with methanol as the working fluid, the coalescence or break-up is limited because of the low surface tension of this fluid. In that case, the liquid plugs are longer than with water.

As regards numerical investigations, Khandekar et al. [4] developed semi-empirical models based on the experimental results obtained by Charoensawan et al. [8]. Wong et al. [9] proposed a PHP knowledge model that was improved by Shafii at al. [10]. Liang and Ma [11] studied the effect of different parameters thanks to a model close to that by Shafii et al. [10]. Dobson et al. [12] presented a model of an open PHP. It consists of a U-shaped capillary tube whose extremities are placed in a liquid tank. The U-part of the capillary is heated. This numerical model takes into account the presence, or not, of the liquid film on the wall and predicts oscillations in the fluid flow. 
Numerical results usually show a contradiction with experimental distribution of the vapour plugs, because the vapour plug break-up phenomena are not taken into account. In addition, the vapour plugs or liquid slugs are not symmetric [13], which induces a capillary pressure difference at their ends. This term is usually not included in the numerical models.

In this article, some experimental results obtained with a full-size PHP will first be analysed. We will particularly focus on the effect of the fluid and tube diameter, as well as the effect of orientation. Then, to help us analyse the results obtained at the system scale, we will discuss the results of an experimental study of the oscillating flow in a single tube of a single liquid plug, under adiabatic conditions (purely hydrodynamic aspect) and under non-adiabatic conditions (thermal effects due to heating of the test-section).

\section{Experiments with full-size PHPs}

\subsection{Experimental set-up}

Two different open loop PHPs made of a single copper tube were built, as shown schematically on Fig. 1. A valve situated between the two ends of the tube of each PHP allows the operation either in open- or closed-loop configuration. Nevertheless, in the following, only results obtained in the open-loop configuration are presented. The inner diameter of the tube used for the first PHP (PHP1) is $\mathrm{D}_{1}=1.2 \mathrm{~mm}$ and $\mathrm{D}_{2}=2.5 \mathrm{~mm}$ for PHP2. The working fluid for PHP1 is water, and that for PHP2 is acetone. It is worth underlining that the critical diameter for water is about $5 \mathrm{~mm}$ in the investigated range of temperature, i.e. about 4 times the tube diameter for PHP1. The critical diameter for acetone is 
only slightly higher than the tube diameter $\left(D_{\text {crit }}=3.2 \mathrm{~mm}\right.$ for the considered range of operating temperature, i.e. about 1.3 times the tube diameter for PHP2).

For each PHP, the capillary tube has been wound around $\left(\mathrm{N}_{1}=40\right.$ turns for PHP1, and $\mathrm{N}_{2}$ $=20$ turns for PHP2) two copper blocks which form the evaporator (length $=180 \mathrm{~mm}$ ) and condenser (length $=200 \mathrm{~mm}$ ) and which allow for thermal spreading. The adiabatic zone length is $190 \mathrm{~mm}$. Heat is supplied to the evaporator by several cartridge heaters (max power $6 \mathrm{~kW}$ ) and the condenser is cooled by a flow of a water-glycol mixture whose temperature is controlled by means of a cryostat. The PHPs can be operated either horizontally or vertically under adverse or favourable orientations (i.e. condenser above or below evaporator). Both PHPs are equipped with $24 \mathrm{~K}$-type thermocouples distributed all-along their length. All the results presented in the following part have been obtained under steady-state conditions: the coolant temperature at the condenser and the heating power at the evaporator were first fixed to the desired value by the experimenter, and then the temperatures were recorded when they had reached a value independent from time. Both PHPs are filled up to a filling ratio (i.e. ratio of the volume of liquid measured at $20^{\circ} \mathrm{C}$ to the whole inner volume of the PHP) equal to $50 \%$. It has been shown (e.g. in [3]) that the filling ratio is a parameter of major effect on the PHP behaviour, and that filling ratios between $40 \%$ and $60 \%$ usually allow for minimizing the overall thermal resistance of the system.

\subsection{Experimental results}

Experimental results for characterisation can be described from the temperatures at the evaporator and condenser and heat rate, or, as chosen in the following, in terms of overall thermal resistance, which is defined from the heat rate $(\dot{\mathrm{Q}})$, the average copper block 
temperature at the evaporator $\left(\mathrm{T}_{\mathrm{e}}\right)$ and the average coolant temperature at the cryostat cooling the condenser $\left(\mathrm{T}_{\text {cryo }}\right)$ :

$$
\mathrm{R}=\frac{\mathrm{T}_{\mathrm{e}}-\mathrm{T}_{\text {cryo }}}{\dot{\mathrm{Q}}}
$$

A large number of other experimental results were obtained by Bensalem [14] on the same experimental bench in other operating conditions.

Figures 2 and 3 respectively represent the thermal resistance of PHP1 (water, D $=1.2 \mathrm{~mm}$ ) and PHP2 (acetone, D = 2.5 mm) as a function of the heat rate and for a horizontal orientation $\left(\right.$ denoted $0^{\circ}$ ), a favourable vertical orientation $\left(\right.$ denoted $+90^{\circ}$ ) and an unfavourable vertical orientation (denoted $-90^{\circ}$ ). To a certain extend, the effect of orientation is a clue for understanding the effect of gravity on the system, which is of uttermost importance in the context of space applications that are often evoked as motivations of works on PHPs. In case of vertical orientation, gravity is expected to assist the flow of liquid from the condenser to the evaporator if the former is located above the latter. On the contrary, for a condenser below the evaporator, the flow of liquid is restricted because of the static head.

It is worth underlining that even in vertical unfavourable orientation, both PHP1 and PHP2, operating in open- loop configuration, were able to operate over a relatively large range of heat rate. In addition, even for the highest heat rate plotted on the graphs, the system would not deprime and stop. With such high heating powers, the evaporator temperature reached the maximum acceptable value for the safety of the test bench or of the instrumentation.

For both PHPs, and whatever the orientation, the overall thermal resistance decreases when increasing the heat rate. One should nevertheless observe that for PHP2 (Fig. 3), two behaviours can be detected. At low heat flux, the operating curves are relatively irregular, but 
beyond a certain threshold value of heat rate (about $1300 \mathrm{~W}$ ), they become much smoother. In addition, at low heat flux, and in spite of the mentioned irregular behaviour, a favourable orientation can be viewed as roughly leading to lower thermal resistance than in unfavourable orientation. On the contrary, at high heat flux, the orientation has almost no impact on the thermal resistance. The behaviour of PHP1 is different in that sense that the orientation seems here to never affects the thermal resistance. One should first recall that the number of turns $\mathrm{N}$ is different for these PHPs. The number of turns is known to influence the performance of PHPs: especially, increasing the number of turns reduces the effect of gravity on their behaviour $[8,15]$. Several explanations were proposed for this observation. Firstly, increasing $\mathrm{N}$ increases the interconnexions in the PHP, which is thought to improve the heat transfer [8, $15,16]$. Secondly, for a constant tube diameter, increasing $\mathrm{N}$ increases the overall heat transfer area between the fluid and the wall. However, here, the higher number of turns is accompanied by a lower value of diameter. As a consequence, in the present case, the ratio of heat transfer area in the evaporator zone between PHP1 and PHP2 $\left(\mathrm{N}_{1} \cdot \mathrm{D}_{1}\right) /\left(\mathrm{N}_{2} \cdot \mathrm{D}_{2}\right)$ is very close to unity. Lastly, the ratio between the total cross-section for the fluid flow in all tubes of PHP1 compared to PHP2 $\left(\left(\mathrm{N}_{1} \cdot \mathrm{D}_{1}^{2}\right) /\left(\mathrm{N}_{2} \cdot \mathrm{D}_{2}^{2}\right)\right)$ is about 0.5 . This means that the hydraulic resistance in PHP2 is lower than in PHP1. Moreover, as the diameter of PHP1 is low compared to the critical value (cf. eq. (1)) and as the operating curves of PHP2 are independent from orientation for high heat fluxes, we conclude that the impact of tube diameter on the independence of the thermal resistance against the orientation is higher than that of number of turns, a value which is in any case already relatively high $\left(\mathrm{N}_{2}=20\right)$ with respect to the observations of the literature on that issue. Finally, one can add that for PHP1, the operating curve is smooth over the whole range of heat rate, so that only one type of 
behaviour can be detected. In other words, the whole operating curve obtained for PHP1 is apparently in the "high heat flux" regime as it has been described for PHP2.

Nevertheless, for both PHPs, the maximum heat rate before the safety temperature is reached is lower in unfavourable orientation than in favourable or horizontal orientation.

\section{Experiments at the scale of a single capillary tube}

For better understanding some of the phenomena involved in PHPs, and particularly the existence of the two operating regimes described above, a specific experimental set-up dedicated to the analysis of oscillating two-phase flows in a single capillary tube was designed and built. The aim of such a study at the scale of a single tube, while real PHPs usually include a large number of meandering turns, is to focus on some effects that are discussed in the following while eliminating other effects. In other words, this experimental work will not explain all the phenomena involved in PHPs, but will reveal two of them. As a matter of fact, we will see that such a design will allow bringing to the fore the effect of the dissymmetry of the oscillating vapour plugs (i.e. the effect of the capillary pressure between the ends of the plus) and the impact of the phase-change on the oscillating two-phase flow. These phenomena obviously exist in real PHPs, but they are mixed with other phenomena such as bubble break-up in U-bends, as reported by Xu et al. [7], cf. section 1.

\subsection{Experimental set-up}

A schematic of the test bench is shown in Fig. 4. It mainly consists of two tanks connected by a capillary tube. A variable frequency electric motor enables to impose a quasi-sinusoidal 
volume variation on the upstream tank (also called "variable pressure reservoir") through an eccentric wheel, and a flexible membrane mounted with a return spring. The capillary is a 2.4 $\mathrm{mm}$ inner and $4 \mathrm{~mm}$ outer diameter glass tube. Its length is $30 \mathrm{~cm}$. It is connected to the tanks by means of Rilsan ${ }^{\mathrm{TM}}$ pipes. The downstream tank (also called "constant pressure reservoir") is filled with liquid pentane in equilibrium with its vapour, whereas the upstream tank contains only vapour pentane. Pentane was chosen for the convenience of experiments: its boiling point is $36^{\circ} \mathrm{C}$, which makes the experiments easier than with water for example, and limits the risks of breaking the tubes or reservoir because of high pressures or high temperatures.

The amplitude of the pressure oscillation (about 0.1 bar) and the frequency (typically $4 \mathrm{~Hz}$ ) are adjusted so as to represent typical measurements of these values on a branch of the fullscale PHPs [14]. This adjustment can be done practically by modifying the hydraulic resistance to the liquid flow in the capillary tube (i.e. by modifying the length of capillary tube and the length of liquid slug) and by choosing the appropriate strength of the return spring and eccentricity of the eccentric wheel.

Thermocouples and manometers are located in the tanks in order to check the absence of noncondensable gases: the temperature must be in agreement with the saturation temperature corresponding to the pressure prior to starting any experiment. The flow is visualized thanks to a high speed camera. The studied flow consists of only one liquid slug oscillating in the capillary. Tests and visualizations were first made under adiabatic conditions at ambient temperature, in order to reveal some features of the two-phase flow in the absence of phasechange and heat transfer phenomena. Then, experiments were made when the tube was inserted into a heated copper block in which an opening was pierced to allow for the flow visualisation in the heated tube section. These non-adiabatic experiments are useful for 
understanding the effect of phase-change (nucleation, evaporation) on the oscillating flow, which remains imposed by the motor and its action on the variable volume reservoir.

\subsection{Adiabatic experiments: hydrodynamic aspects}

The oscillation of the slug is illustrated in Fig. 5, which represents a set of photographs at different times. The time step between two frames is equal to $20 \mathrm{~ms}$. Here, advancing and receding menisci refer to the liquid plug motion: advancing corresponds to the leading edge and receding to the tail of the liquid plug. Enlargements (a), (b) and (c) show a strong dissymmetry of left and right interfaces: the curvature radius of advancing menisci (right interface in (a) and left interface in (c)) is smaller than that of receding menisci. This dissymmetry is a view of the pressure difference between both sides of the liquid slug. In case (b), the interface velocity is equal to zero and the liquid slug is then symmetric.

An image post-processing program has been developed to determine the position of the interfaces and the meniscus curvature radii for each visualization frame. The automation of this task allows having a lot of measurements and enables to verify their repeatability. During visualization, several periods are recorded. Figure 6 is an example of the time evolution of the curvature radii of the two interfaces. In that experiment, the liquid slug velocity oscillates between -0.2 and $+0.3 \mathrm{~m} / \mathrm{s}$. A negative velocity relates to a receding meniscus, while a positive velocity relates to an advancing one. Eight periods of oscillation are recorded and superposed. The average evolution over these eight periods is represented as dotted line: a good repeatability is observed from one period to another.

A large number of experiments were done for various conditions: the liquid slug length ranged from 2.4 to $15.2 \mathrm{~mm}$, the amplitude of the velocity oscillations could reach up to 
$0.65 \mathrm{~m} / \mathrm{s}$, and the frequency of the imposed sinusoidal evolution of the pressure ranged from 1.8 to $6.1 \mathrm{~Hz}$, which is believed to be the correct order of magnitude in PHPs. The experimental results are presented as the superposition of curves showing the inverse of the dimensionless meniscus curvature radius $r^{*}$ vs. meniscus velocity u (Fig. 7). No clear effect of the slug length or frequency could be detected, and all the curves are roughly correlated by a linear fit as $\frac{1}{\mathrm{r}^{*}}=\frac{\mathrm{D}}{2 \mathrm{r}}=-0.83 \mathrm{u}+0.88$. This correlation does not aim at being general: it is only valid for our experiment, but it will help us in the following for analysing the results. Indeed, this correlation can be used to assess the impact of the slug capillary pressure difference between advancing and receding menisci on the two-phase flow, i.e. the importance of the slug dissymmetry. For that purpose, we consider as an example a liquid slug of length $L=1 \mathrm{~cm}$ whose maximum velocity is $\mathrm{u}=0.5 \mathrm{~m} / \mathrm{s}$. According to the experimental results, the advancing dimensionless radius of curvature is $1 / \mathrm{r}^{*}=0.465$ (i.e. for $\mathrm{u}=0.5 \mathrm{~m} / \mathrm{s}$ ), and that of the receding meniscus is 1.295 (i.e. for $\mathrm{u}=-0.5 \mathrm{~m} / \mathrm{s}$ ). Therefore, the capillary pressure difference reaches $10.9 \mathrm{~Pa}$ for pentane at $20^{\circ} \mathrm{C}(\sigma=15.2 \mathrm{mN} / \mathrm{m})$ in the $2.4 \mathrm{~mm}$ inner diameter tube used in the experiments. Besides, the frictional pressure drop for the liquid slug is calculated as $\Delta \mathrm{P}_{\mathrm{f}}=2(\mathrm{~L} / \mathrm{D}) \times 0.078\left(\rho_{1} \mathrm{uD} / \mu_{1}\right)^{-0.25} \times \rho_{1} \mathrm{u}_{1}^{2}$. With $\rho_{1}=625.7$ $\mathrm{kg} / \mathrm{m}^{3}$ and $\mu_{1}=2.37 .10^{-4}$ Pa.s at $20^{\circ} \mathrm{C}$, the frictional pressure drop for the considered $1 \mathrm{~cm}$ long slug reaches $13.5 \mathrm{~Pa}$, which is of the same order of magnitude as the capillary pressure difference. This short numerical example demonstrates that the dynamic contact angle difference between receding and advancing menisci should definitely be taken into account when trying to model the oscillating process of a PHP, as the capillary pressure difference will be as important as the other main term in the momentum equation for liquid, namely the frictional pressure drop. 
Another aspect of hydrodynamics lies in the existence of wavelets that can be observed at the advancing meniscus (Fig. 8). The liquid film does not smoothly get thicker and thicker from the contact line to the liquid core, but on the contrary, particularly at the moments when the velocity is high, it exhibits an instability which can probably be interpreted from the lubrication theory. Analogous observations and explanations were proposed by Bretherton [17].

This behaviour can also be interpreted from Moriyama and Inoue [18] criterion that relates the film thickness to a Bond number written as:

$$
\mathrm{Bo}=\frac{\rho_{1} \mathrm{D}^{2}}{\sigma} \frac{\mathrm{du}}{\mathrm{dt}}
$$

This number includes the fluid acceleration and represents the ratio of the inertial forces due to acceleration to surface tension forces. These authors stated that the film thickness is governed by hydrodynamics (development of a viscous boundary layer) at high Bo number (i.e. Bo $>2)$, and by capillary effects at low Bond number $($ Bo $<2)$.

In our experiments, the typical velocity amplitude is $0.5 \mathrm{~m} / \mathrm{s}$ and the typical frequency if $4 \mathrm{~Hz}$. With such values, and assuming a perfect sinusoidal evolution of the velocity, the critical velocity for the transition between low and high Bond numbers is about $0.3 \mathrm{~m} / \mathrm{s}$, which was found to be consistent with the development of wavelets in the liquid film. This can also be detected from Figure 7: the dispersion of the measurements around the linear fit is wider for $\mathrm{u}>0.3 \mathrm{~m} / \mathrm{s}$ or $\mathrm{u}<-0.3 \mathrm{~m} / \mathrm{s}$ : in these domains, the presence of wavelets disturbs the automatic image processing, and therefore reduces the accuracy of the measurement of the meniscus radius of curvature. 


\subsection{Thermal aspects: effect of phase-change on the two-phase flow}

In order to study the effect of heat transfer and phase-change on the two-phase flow, the wall superheat $\Delta \mathrm{T}_{\mathrm{sat}}=\mathrm{T}_{\mathrm{w}}-\mathrm{T}_{\text {sat }}$ was fixed to $15 \mathrm{~K}$ or $35 \mathrm{~K}$. The wall temperature was measured at the contact between the heating block in copper and the glass outer wall, but no accurate measurement of the inner glass wall temperature was possible. This is not expected to be major issue in that sense that these fundamental experiments do not aim at providing experimental values of thermal parameters, but rather to understand the processes occurring in the full-size PHPs that were described previously. Two typical video recording sequences are shown on Fig. $9 \mathrm{a}\left(\Delta \mathrm{T}_{\text {sat }}=15 \mathrm{~K}\right)$ and Fig. $9 \mathrm{~b}\left(\Delta \mathrm{T}_{\text {sat }}=35 \mathrm{~K}\right)$. These both sequences are shorter (about $50 \mathrm{~ms}$ ) than the oscillation half-period $(125 \mathrm{~ms})$. In other word, these sequences correspond to a portion of period of the imposed oscillation during which the overall pressure difference between the variable volume reservoir and the constant pressure reservoir is always oriented in the same direction.

For a $15 \mathrm{~K}$ superheat, nucleation takes place at the edge of the advancing meniscus, but the bubble detaches relatively quickly after its birth. Its diameter remains lower than the tube diameter and it follows the overall motion of the liquid plug. The bubble may merge into the advancing liquid plug, but this phenomenon does not affect much the overall motion and it just tends to flatten the advancing meniscus during the coalescence process.

For a $35 \mathrm{~K}$ superheat, in the early stage, nucleation also occurs at the edge of the advancing meniscus, which is comparable to what was observed for $15 \mathrm{~K}$ superheat. But one can see that nucleation also occurs in the middle of the liquid plug and that this second bubble starts growing. This second bubble merges with the vapour plug as it has grown and expanded so rapidly that it could reach the interface. But meanwhile, a third bubble was born and is 
expanding. Its expansion is relatively violent, so that the receding meniscus is deformed. The liquid plug is thus broken up into several smaller plugs. Finally, the expansion of the third bubble is so strong that it forces the remaining liquid plug to flow against the overall imposed pressure difference. In the very late stages of this process, the liquid is fully vaporized. The images show the evaporation of the remaining liquid film.

These two kinds of behaviour must certainly be related to the two kinds of behaviour of the full-scale PHPs described in section 2.2. Indeed, a lower heat input leads to relatively low wall superheat, for which small bubbles may be generated by a simple nucleation process. Nucleation is well known to be a complex process, whose repeatability is relatively poor. This might explain the "chaotic" behaviour of the thermal resistance of the PHP vs. heat flux curves at low heat flux (lower than about $1300 \mathrm{~W}$, cf. Figs. 2 and 3). This only occurs for acetone (PHP2), because the typical diameter of the bubbles will remain lower than the tube diameter. Obviously, in such a case, and if the tubes are oriented vertically, the bubbles are likely to carry up some liquid with them, as suggested by Khandekar et al. [5]. On the contrary, at high heat flux (high superheat), the heat transfer is governed by thin film evaporation which is not sensitive to orientation, and this may be an explanation for the independence of thermal resistance to orientation. Nevertheless, one could notice that the maximum heat input rate allowed by the real PHPs is higher in favourable than in unfavourable orientation. In spite of the impact of the fast thermal expansion of bubbles on the flow, the bubbles may probably still carry up some liquid with them.

\section{Conclusion}

Two separate experiments have been built and used in this work in order to characterize two full-size open loop pulsating heat pipes (PHP) and to visualize oscillating two-phase flow 
phenomena occurring in a single capillary tube (typical of PHPs) subjected to controlled pressure oscillations and/or wall superheat.

Concerning the full-size PHPs, the experiments reveal that both tested PHPs can operate whatever the inclination, even in vertical unfavourable inclination. However, the performance in the latter case remains lower than in horizontal or favourable inclination. Moreover, it has been shown that the overall thermal resistance of the two PHPs decreases with increasing heat power, except for the large diameter PHP (filled with acetone) subjected to the lowest heat transfer rates: in such conditions, the operative curve (PHP overall thermal resistance vs. heat transfer rate) seems to be more chaotic.

The single tube experiments were done to highlight or reveal some phenomena that are usually mixed with other when they occur in real PHPs, but whose analysis is easier in a single tube. One can first conclude that the differences between the advancing and receding meniscus radii surrounding the liquid plug have to be taken into account in the models, because the induced capillary pressure difference is of the same order of magnitude as the friction losses. Visualisations also revealed the presence of instabilities (wavelets) at the advancing meniscus. These wavelets develop for velocities that were found in agreement with the critical velocity calculated with a theoretical model from the literature. Their impact on evaporation heat transfer remains to be studied. Finally, when the test section is heated, a 15 $\mathrm{K}$ wall superheat at the evaporator of the tube leads to nucleation of bubbles that are always lower than the tube diameter and that do not affect the overall motion of the plug. On the contrary, a $35 \mathrm{~K}$ wall superheat at the evaporator leads to a faster bubble expansion that deforms the receding meniscus and breaks up the liquid plug into several smaller plugs. This expansion is so strong that it can sometimes lead to make the liquid plug flow against the overall motion which results from the imposed pressure difference between the both ends of 
the tube. These two behaviours are consistent with the trends observed in full-size PHP, especially the two behaviours detected on the operating curves. Such kind of phenomena like the liquid plug motion and bubbles expansion have to be well understood and studied in order to precisely model the heat and mass transfers occurring in PHPs. 


\section{References}

[1] G. Smyrnov, Method of action of the pulsating heat pipe, its construction and the devices on its base, U.S. Patent (2003) Patent No. 0037910.

[2] H. Akachi, Structure of a heat pipe, U.S. Patent (1990) Patent No. 4921041.

[3] S. Khandekar, Thermo-hydrodynamics of closed loop pulsating heat pipe, $\mathrm{PhD}$ thesis, Univ. of Stuttgart, Germany (2004).

[4] S. Khandekar, P. Charoensawan, M. Groll, P. Terdtoon, Closed loop pulsating heat pipes,

Part. B: visualization and semi-empirical modelling, Appl. Therm. Eng. 23 (2003) 2021-2033.

[5] S. Khandekar, N. Dollinger, M. Groll, Understanding operational regimes of pulsating heat pipes: an experimental study, Appl. Therm. Eng. 23 (2003) 707-719

[6] R.R. Riehl., Characteristics of an open loop pulsating heat pipe, National Institute for Space Research (2004) report $n^{\circ} 2004-01-2509$.

[7] J.L. Xu, Y.X. Li, T.N. Wong., High speed flow visualization of a closed loop pulsating heat pipe, Int. J. Heat Mass Transfer 48 (2005) 3338-3351.

[8] P. Charoensawan, S. Khandekar, M. Groll, P. Terdtoon, Closed loop pulsating heat pipesPart A: Parametric Experimental Investigations, Appl. Therm. Eng. 23 (2003) 2009-2020.

[9] T.N. Wong., B.Y. Tong, S.M. Lim, K.T. Ooi, Theoretical modeling of pulsating heat pipe, in: Proc. of the $11^{\text {th }}$ IHPC, Tokyo, Japan, 1999, pp. 159-163.

[10] M.B. Shafii, A. Faghri, Y. Zhang, Thermal modeling of unlooped and looped pulsating heat pipes, J. Heat Transfer 123 (2001) 1159-1172.

[11] Liang S. B., Ma H. B., Oscillating motions of slug flow in capillary tubes, Int. Comm. Heat Mass Transfer 31 (2004) 365-375.

[12] R.T. Dobson, An open oscillatory heat pipe water pump. Appl. Therm. Eng. 
25 (2004) 603-621.

[13] S. Khandekar, M. Schneider, P. Schäfer, R. Kulenovic, M. Groll, Thermofluiddynamic study of flat plate closed loop pulsating heat pipe, Micr. Therm. Eng. 6(4) (2002) 303-318 [14] A. Bensalem, Contribution à l'analyse du comportement de caloducs oscillants à finalité spatiale par voies expérimentale et numérique. PhD Thesis, Univ. Poitiers, France, 2008 [15] S. Khandekar, A.P. Gautam, P.K. Sharma, Multiple quasi-steady states in a closed loop pulsating heat pipe, Int. J. Heat Mass Transfer 48 (2009) 535-546

[16] B.Y. Tong, T.N. Wong, K.T. Ooi, Closed-loop pulsating heat pipe, Appl. Therm. Eng. 21 (2001) $1845-1862$

[17] F.P. Bretherton, The motion of long bubbles in tubes. J. Fluid Mech. 10(02) (1961) 166188

[18] K. Moriyama, A. Inoue, Thickness of the liquid film formed by a growing bubble in a narrow gap between two horizontal plates, J. Heat Transfer 118 (1996) 132-139

\section{Aknowledgments}

This work was partially sponsored by Centre National des Etudes Spatiales (CNES), especially under the form of Dr. A. Bensalem's doctoral grant. This work was also conducted in the frame of the CNRS National Thematic Network devoted to phase-change cooling systems (SYREDI, "Systèmes de Refroidissement Diphasique", GdR2613). 


\section{Figure Captions}

Fig. 1: Schematic of the PHP and experimental apparatus

Fig. 2: Overall thermal resistance vs. heat rate for open loop PHP1 (water, $\mathrm{D}_{1}=1.2 \mathrm{~mm}, \mathrm{~N}_{1}=$ 40)

Fig. 3: Overall thermal resistance vs. heat rate for open loop PHP2 (acetone, $\mathrm{D}_{2}=2.5 \mathrm{~mm}, \mathrm{~N}_{2}$ $=20$ )

Fig 4: Experimental device for the experiments at the scale of a PHP single branch

Fig. 5: Visualization of the oscillation liquid slug motion

Fig. 6: Typical time-evolution of the meniscus curvature radius

Fig. 7: Linear regression for the dimensionless meniscus radius as a function of interface velocity

Fig. 8: Advancing and receding menisci, with the presence of wavelets in the liquid film close to the advancing meniscus

Fig. 9: Visualisation of the flow and the impact of bubble nucleation and expansion for two wall superheats 


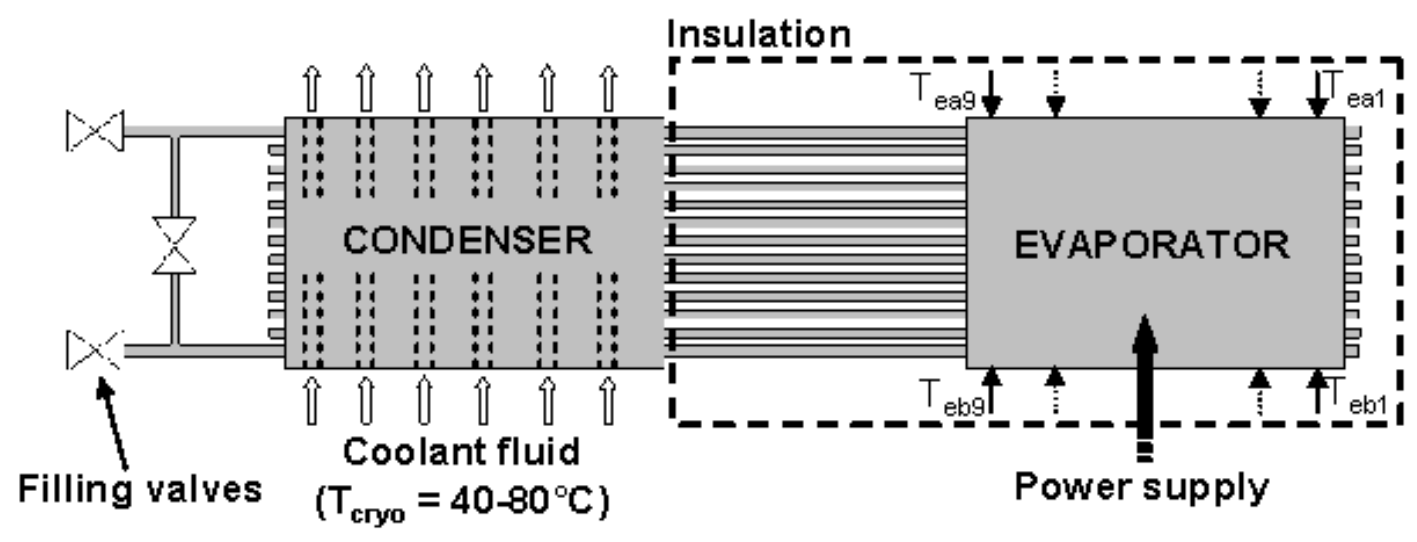




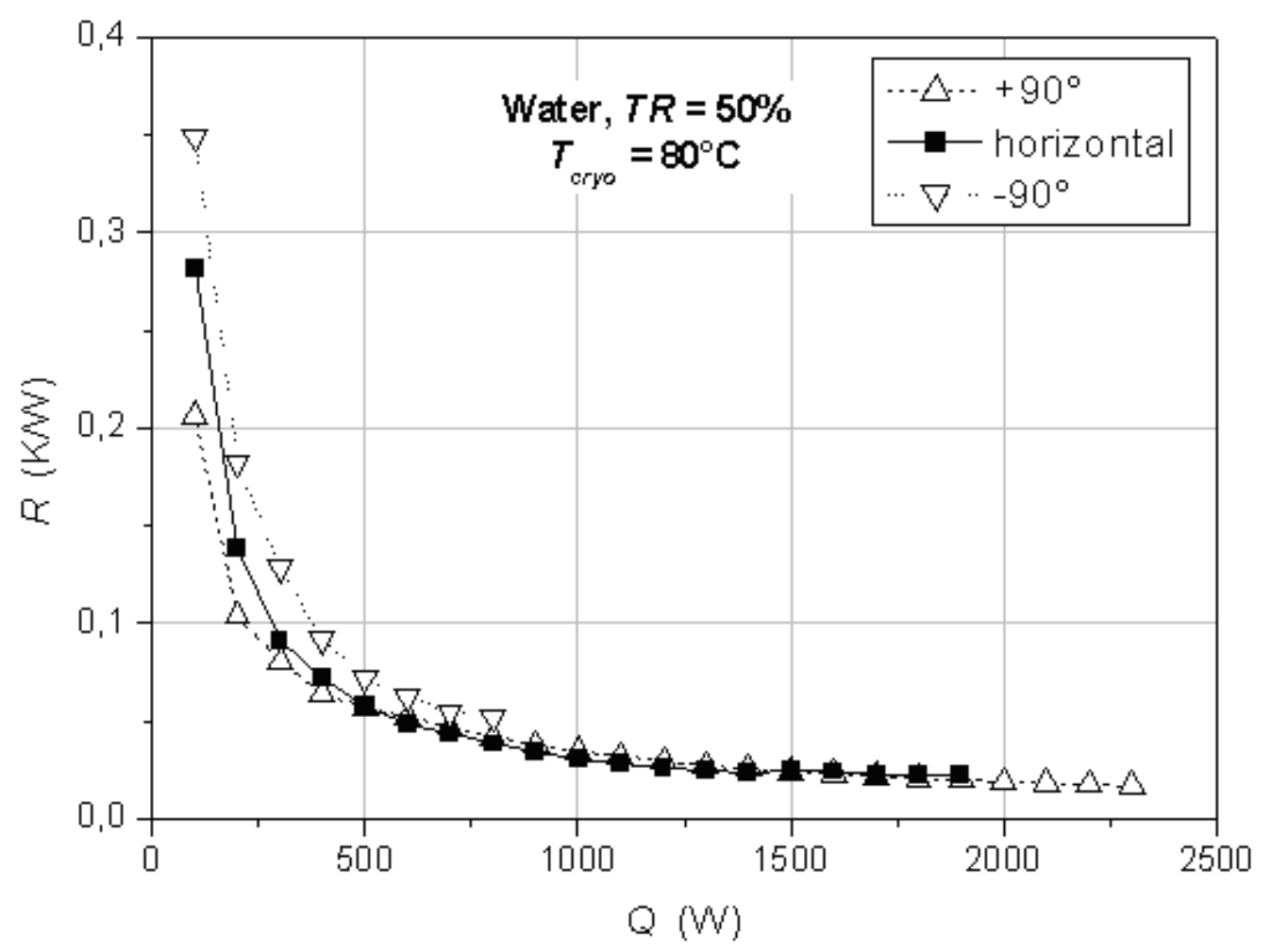




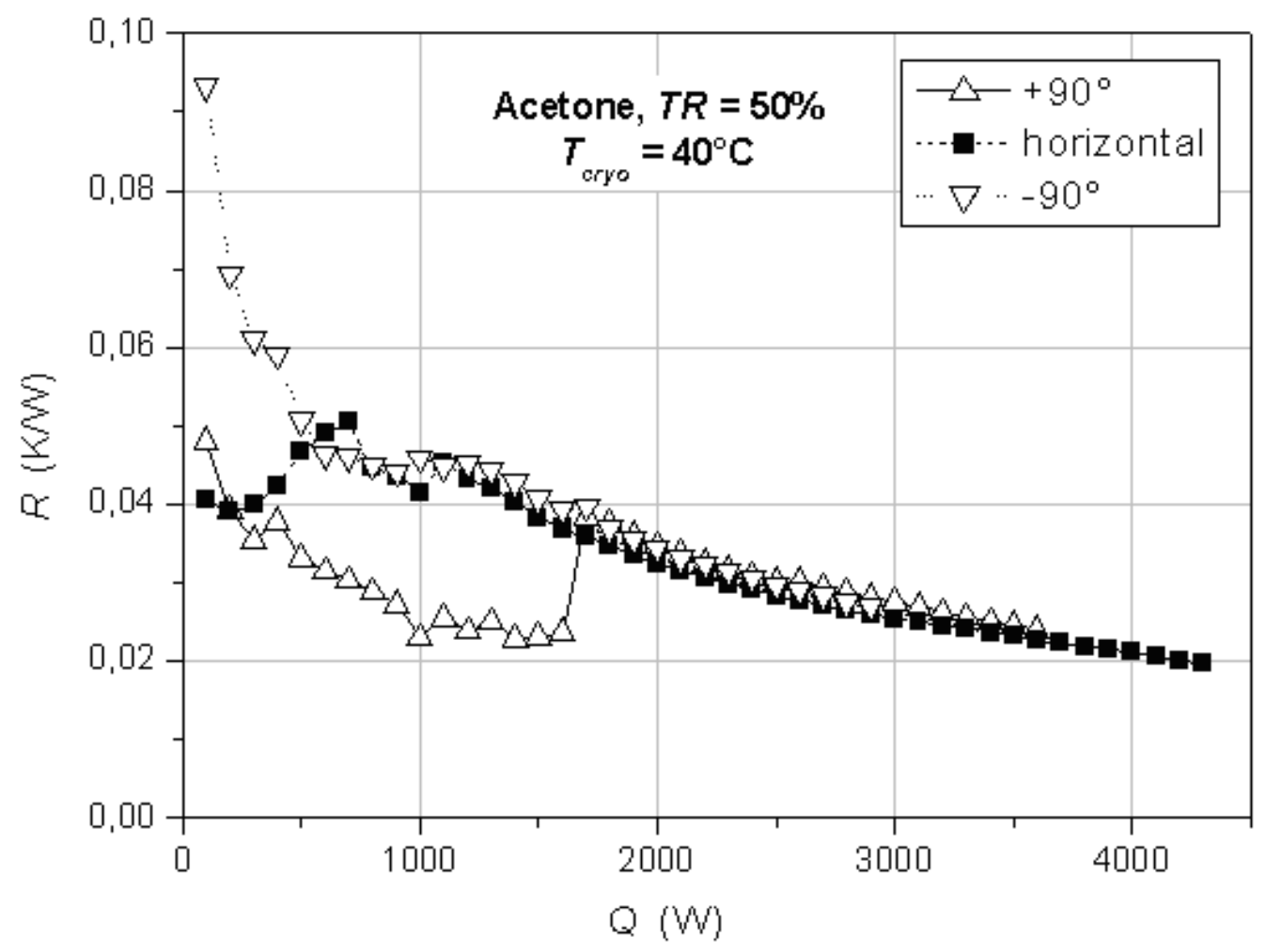




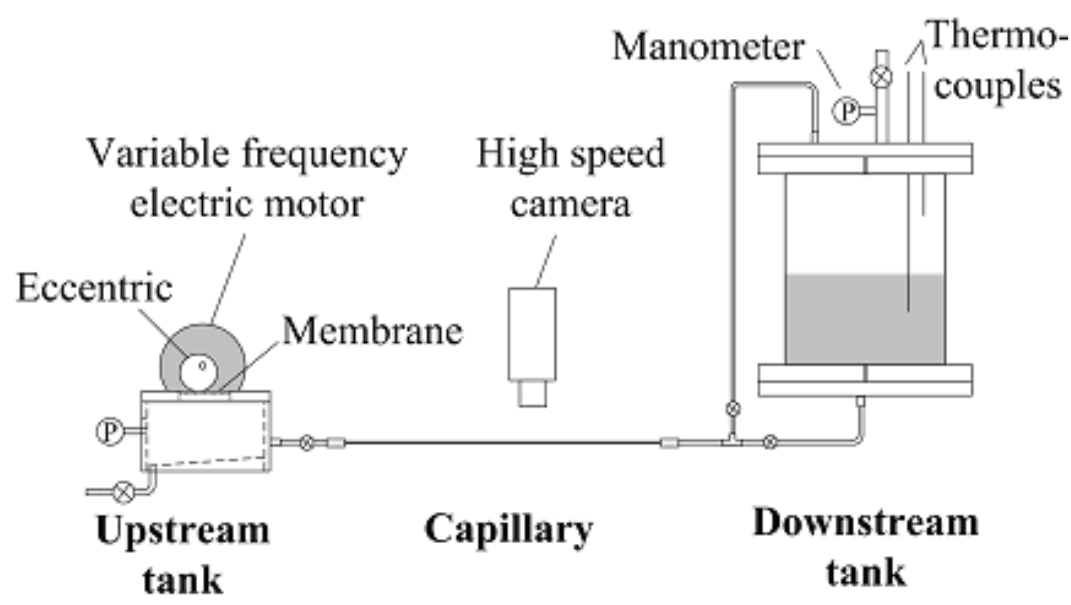



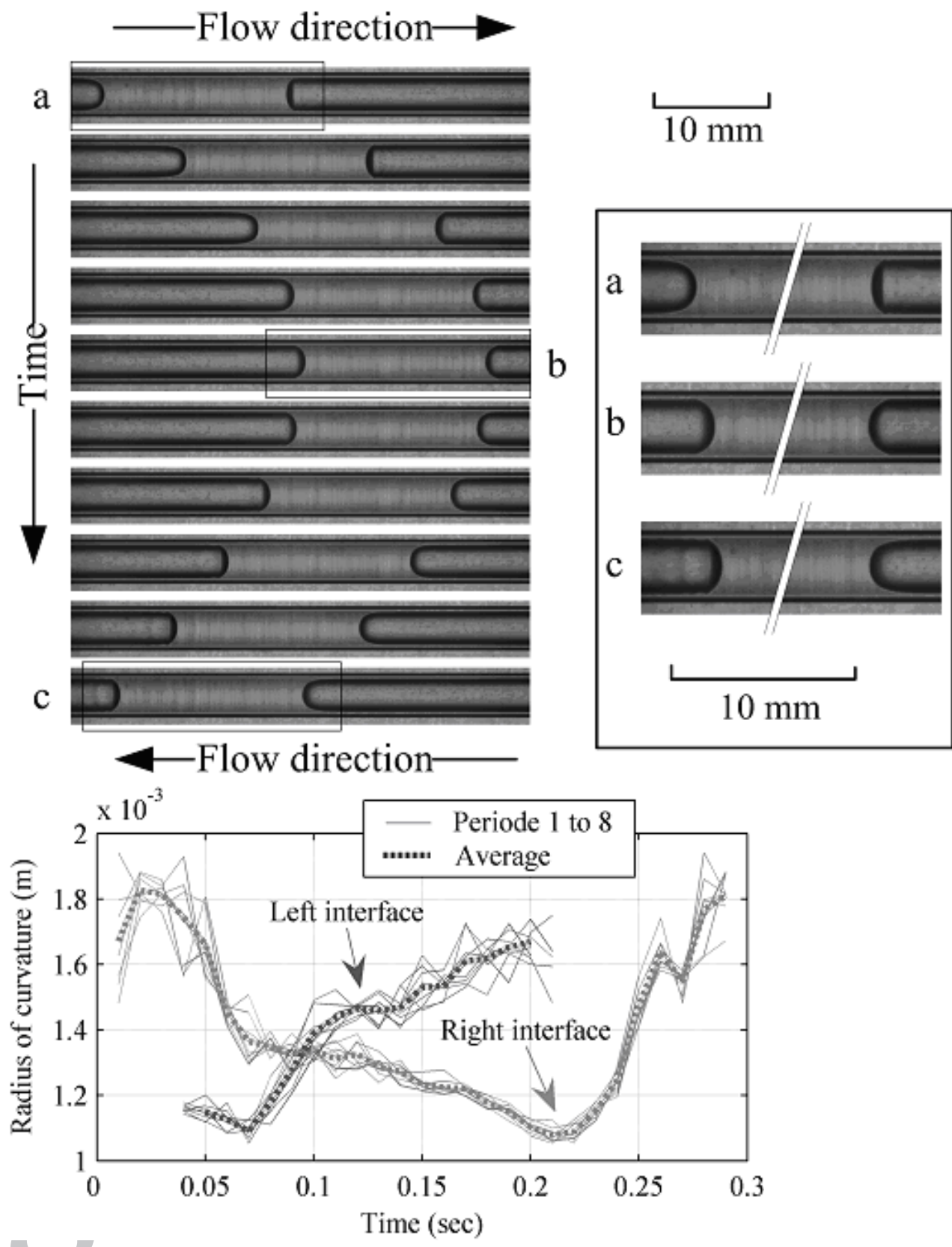


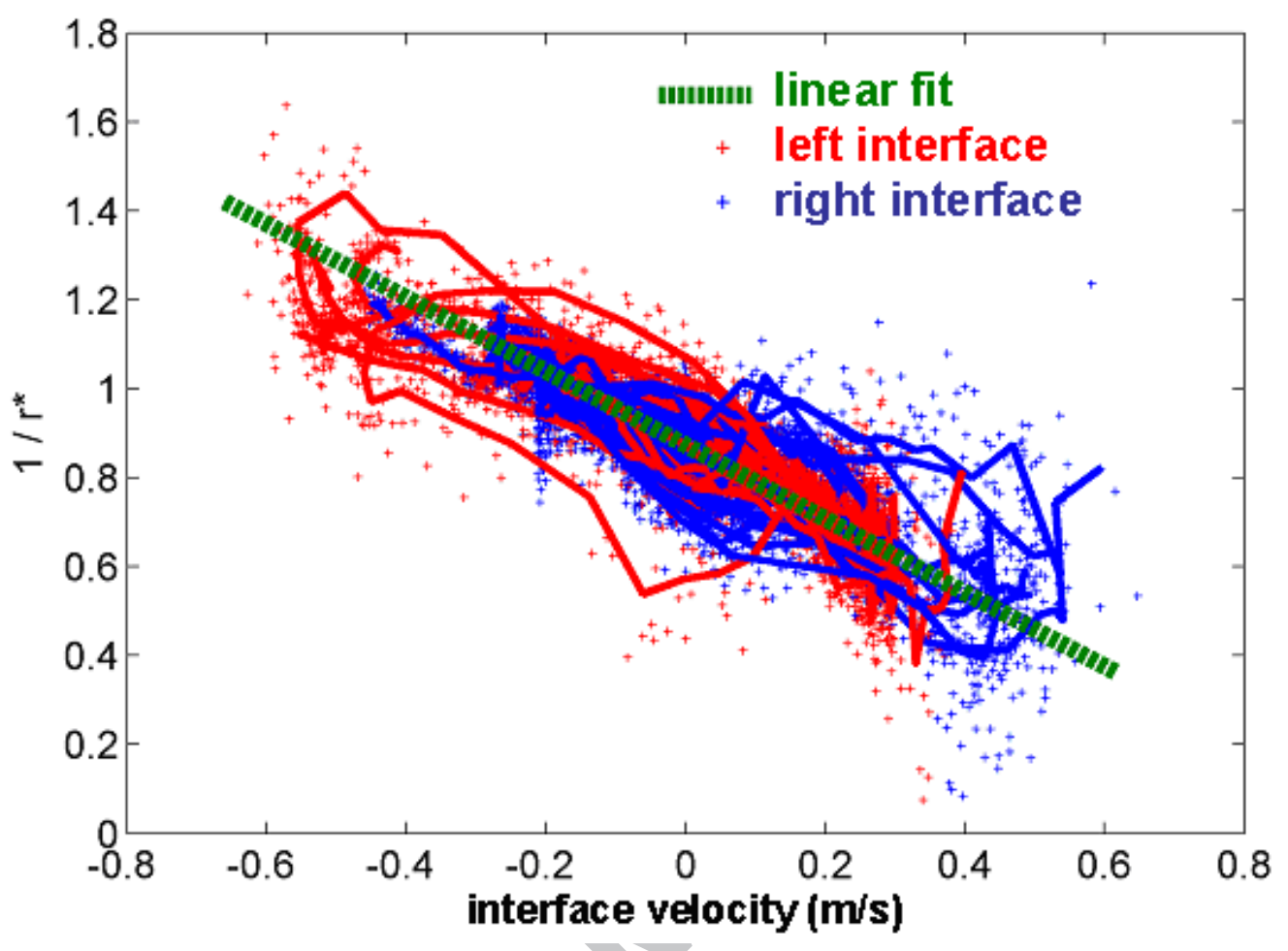




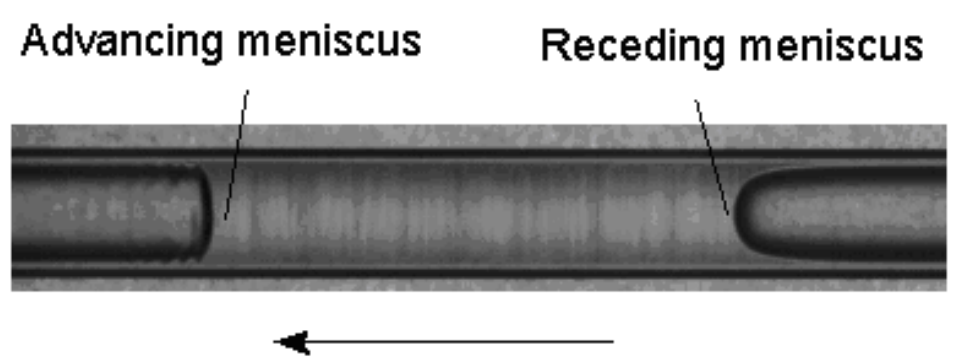

Fluid flow 


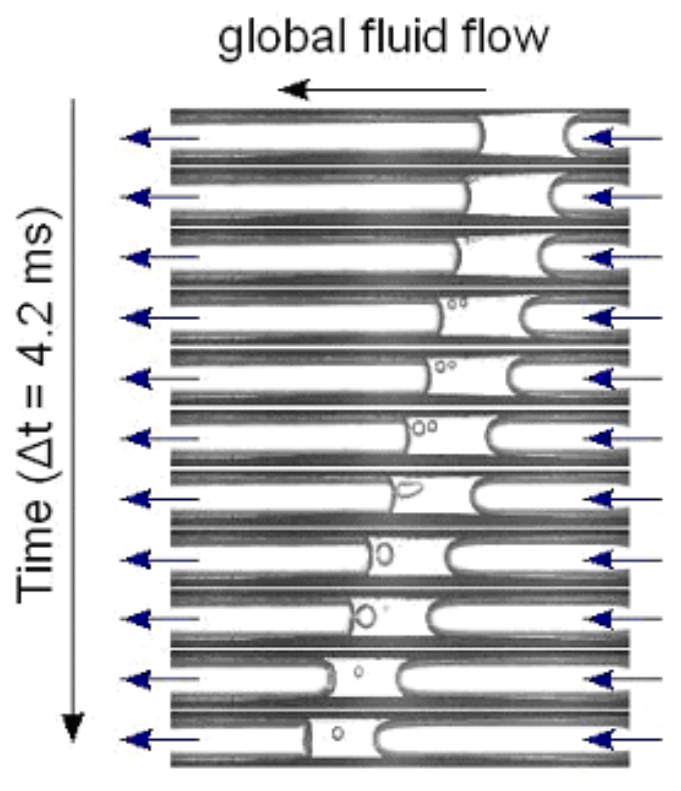

(a) $\Delta T=15 \mathrm{~K}$

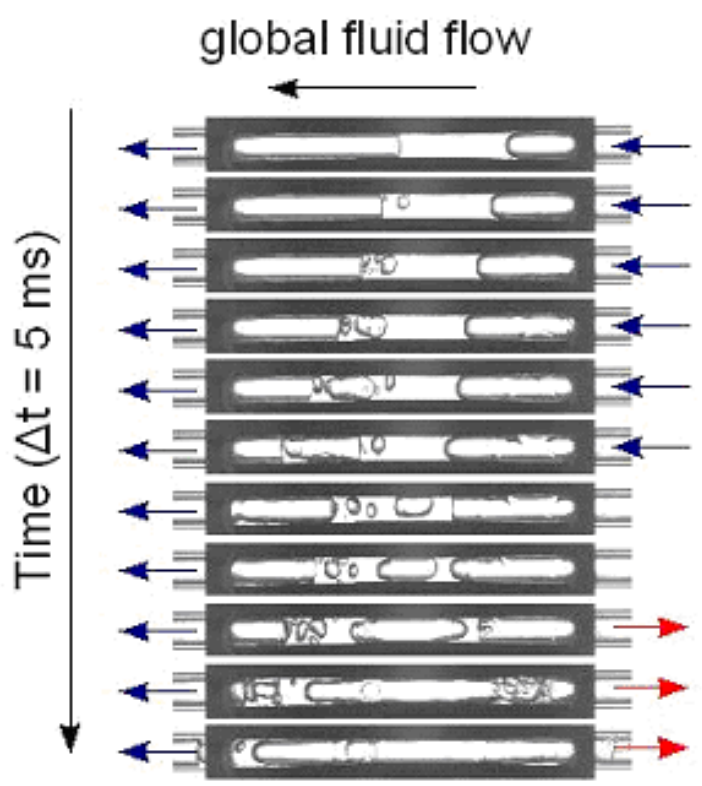

(b) $\Delta T=35 \mathrm{~K}$ 